\title{
ERK-mediated phosphorylation of BIS regulates nuclear translocation of HSF1 under oxidative stress
}

\author{
Hye Yun Kim ${ }^{1,2}$, Yong-Sam Kim ${ }^{3,4}$, Hye Hyeon Yun ${ }^{1,2}$, Chang-Nim Im $^{1,2}$, Jeong-Heon Ko ${ }^{3,4}$ \\ and Jeong-Hwa Lee ${ }^{1,2}$
}

B-cell lymphoma (BCL)-2-interacting cell death suppressor (BIS) has diverse cellular functions depending on its binding partners. However, little is known about the effects of biochemical modification of BIS on its various activities under oxidative stress conditions. In this study, we showed that $\mathrm{H}_{2} \mathrm{O}_{2}$ reduced BIS mobility on SDS-polyacrylamide gels in a time-dependent manner via the activation of extracellular signaling-regulated kinase (ERK). The combined results of mass spectroscopy and computational prediction identified Thr285 and Ser289 in BIS as candidate residues for phosphorylation by ERK under oxidative stress conditions. Deletion of these sites resulted in a partial reduction in the $\mathrm{H}_{2} \mathrm{O}_{2}$-induced mobility shift relative to that of the wild-type BIS protein; overexpression of the deletion mutant sensitized $\mathrm{A172}$ cells to $\mathrm{H}_{2} \mathrm{O}_{2}$-induced cell death without increasing the level of intracellular reactive oxygen species. Expression of the BIS deletion mutant decreased the level of heat shock protein (HSP) 70 mRNA following $\mathrm{H}_{2} \mathrm{O}_{2}$ treatment, which was accompanied by impaired nuclear translocation of heat shock transcription factor (HSF) 1. Co-immunoprecipitation assays revealed that the binding of wild-type BIS to HSF1 was decreased by oxidative stress, while the binding of the BIS deletion mutant to HSF1 was not affected. These results indicate that ERKdependent phosphorylation of BIS has a role in the regulation of nuclear translocation of HSF1 likely through modulation of its interaction affinity with HSF1, which affects HSP70 expression and sensitivity to oxidative stress.

Experimental \& Molecular Medicine (2016) 48, e260; doi:10.1038/emm.2016.84; published online 23 September 2016

\section{INTRODUCTION}

B-cell lymphoma (BCL)-2-interacting cell death suppressor (BIS), also known as BCL-2-associated athanogene 3 or carboxyamido-triazole-stressed-1, is a BCL-2-interacting protein that enhances the anti-apoptotic activity of BCL-2. ${ }^{1-3}$ The pro-survival activity of BIS is shown by its increased expression in a variety of human cancers, including lymphocytic leukemia, melanoma, glioma and thyroid, pancreatic and ovarian cancers. ${ }^{4-9}$ BIS expression has also been shown to be induced by stress, such as heat shock, heavy metal treatment, oxidative stress and viral infections, suggesting a role for BIS in cellular homeostasis under conditions of cellular stress. ${ }^{10-12}$

The diverse functions of BIS are attributable to its ability to interact with various proteins via specific domains. For example, the BCL-2-associated athanogene domain is reported to interact with BCL-2 or heat shock protein (HSP) to exert anti-apoptotic and anti-stress effects, ${ }^{13}$ while the proline-rich domain is essential for interaction with phospholipase $\mathrm{C} \gamma$ and modulation of migration/invasion. ${ }^{14}$ Furthermore, two IPV motifs are required for the binding of BIS to HSPB8 to initiate autophagy. ${ }^{15}$

In addition to specific domains in the BIS protein, biochemical modification of the BIS protein has also been shown to influence the interactions between BIS and specific binding proteins and the subsequent cellular phenotypes. Tyr phosphorylation of BIS following epidermal growth factor stimulation is essential for phospholipase C binding, ${ }^{14}$ while phosphorylation of BIS at S136 or S172 is important for its interaction with 14-3-3. ${ }^{16}$ In addition, protein kinase (PK) C8mediated phosphorylation of BIS at residue S187 has been implicated in epithelial-mesenchymal transition and the invasiveness of thyroid cancer cells. ${ }^{17} \mathrm{~A}$ recent study showed that following glucose stimulation, BIS was phosphorylated by focal adhesion kinase, which led to F-actin remodeling. ${ }^{18}$

In previous studies, we showed that BIS was markedly upregulated in reactive hippocampal astrocytes after transient forebrain ischemia ${ }^{19}$ and that downregulation of BIS sensitized C6 rat glioma cells to oxygen-glucose deprivation-induced

\footnotetext{
${ }^{1}$ Department of Biochemistry, College of Medicine, The Catholic University of Korea, Seoul, Republic of Korea; ${ }^{2}$ Institute for Aging and Metabolic Diseases, College of Medicine, The Catholic University of Korea, Seoul, Republic of Korea; ${ }^{3}$ Aging Intervention Research Center, Aging Research Institute, KRIBB, Daejeon, Republic of Korea and ${ }^{4}$ Korea University of Science and Technology. Daejeon, Republic of Korea

Correspondence: Professor J-H Lee, Department of Biochemistry, College of Medicine, The Catholic University of Korea, 222, Banpo-daero, Seocho-gu, Seoul 06591, Republic of Korea.
}

E-mail: leejh@catholic.ac.kr

Received 1 May 2016; revised 10 May 2016; accepted 12 May 2016 
reactive oxygen species (ROS) accumulation and cell death. ${ }^{20}$ Furthermore, BIS-haploinsufficient mice showed increased ROS and oxidative stress, resulting in aggravation of diabetic nephropathy. ${ }^{21}$ These results suggest that BIS protects against ROS, although the underlying mechanism is unclear.

The present study addressed this question by investigating the expression and phosphorylation of BIS under oxidative stress conditions in various cell lines. We found that BIS was phosphorylated by extracellular signal-regulated kinase (ERK) following $\mathrm{H}_{2} \mathrm{O}_{2}$ treatment and that this post-translational modification is the mechanism by which BIS modulates the sensitivity of cells to ROS via regulation of heat shock factor (HSF) 1-dependent transactivation of HSP70.

\section{MATERIALS AND METHODS}

\section{Cell culture and treatment}

A172 (human glioma cells), A549 (human lung adenocarcinoma cells), and HK2 (human kidney tubule epithelial cells) were purchased from the American Type Culture Collection. A172 cells were cultured in Dulbecco's Modified Eagle Medium, and A594 and HK2 cells were cultured in RPMI supplemented with $10 \%$ fetal bovine serum (Thermo Scientific, Waltham, MA, USA) and $1 \%$ penicillin-streptomycin (Thermo Scientific). Mouse embryonic fibroblasts were prepared from wild-type C57B6 mouse embryos ${ }^{22}$ and grown in Dulbecco's Modified Eagle Medium with 20\% fetal bovine serum. Cells were maintained at $37^{\circ} \mathrm{C}$ in a humidified incubator containing $5 \% \mathrm{CO}_{2}$. After overnight culture, the cells were washed with phosphate-buffered saline (Sigma-Aldrich, St. Louis, MO, USA) and then exposed to $\mathrm{H}_{2} \mathrm{O}_{2}$ at the indicated concentration in glucose/serum-free Dulbecco's Modified Eagle Medium for the indicated times. In some experiments, cell lysates were treated with alkaline phosphatase, or the cells were pretreated with kinase inhibitors $1 \mathrm{~h}$ prior to $\mathrm{H}_{2} \mathrm{O}_{2}$ treatment. U0126 (an extracellular signalregulated kinase (ERK) inhibitor), SB203580 (a p38 inhibitor), and SP600125 (a c-Jun N-terminal kinase (JNK) inhibitor) were purchased from Calbiochem (San Diego, CA, USA). To determine the effects of a ROS scavenger, $1 \mathrm{~mm}$ of N-acetyl-L-cysteine (Sigma-Aldrich) was added to the cells before $\mathrm{H}_{2} \mathrm{O}_{2}$ exposure.

\section{Western blot analysis}

Total cell lysates were prepared as described previously. ${ }^{23}$ Protein concentration was determined using a BCA protein assay (Pierce, Rockford, IL, USA). For subcellular fractionation, a nuclear and cytoplasmic extraction kit, NE-PER (Thermo Scientific), was used according to the manufacturer's instructions. An equal amount of protein for each sample was separated by SDS-PAGE and transferred onto polyvinylidene difluoride membranes (Millipore, Bedford, MA, USA). The blots were incubated with anti-BIS serum, ${ }^{1}$ anti- $\beta$-Actin (Sigma-Aldrich), anti-Lamin B (Santa Cruz Biotechnology, Santa Cruz, CA, USA), or other antibodies against the indicated proteins. The antibodies against HSF1, HSP70, p-p38, p-JNK, p-ERK and p-ELK were purchased from Cell Signaling Technology (Danvers, MA, USA). The blots were then incubated with peroxidase-conjugated antirabbit or mouse immunoglobulin G (Promega, Madison, WI, USA). Visualization of the immunoreactive bands was performed using enhanced chemiluminescence (Thermo Scientific), and the blots were analyzed with LAS-4000 (Fujifilm, Tokyo, Japan). Quantification of the intensities of each band was carried out using Multi Gauge 3.0 software (Fujifilm). The relative densities of the proteins were determined by normalization to that of $\beta$-Actin.

\section{Phosphorylation site analysis}

The BIS protein was immunoprecipitated from A172 cell lysates and separated by SDS-PAGE. Gels were stained with Instant Blue (Coomassie-based gel staining dye that is compatible with mass spectrometry analysis. Expedeon), and the visualized BIS band was excised. In-gel digestion was performed with modified porcine trypsin (Promega), and the peptides were analyzed by liquid chromatographytandem mass spectrometry. The resulting peaks were searched against the SwissProt database (2014.07 release, 20210 sequences for human) using a Mascot Daemon search engine (version 2.4.0, Matrix Science), and the peptides of interest were quantified by peak area integration using the extracted ion chromatograms. We also predicted the phosphorylation motifs of BIS using the Motif Scan program ${ }^{24}$ and Group-based Prediction System 2.0.25

\section{Construction of the BIS plasmid and cell transfection}

The deletion mutant ( $\Delta 281-292$ BIS) was prepared by a two-step PCR protocol and cloned into the pCAGGS vector ${ }^{1}$ or pCMV-myc (Clontech, Mountain View, CA, USA). The transfections of the fulllength (FL) BIS or $\Delta 281-292$ BIS constructs were carried out using Lipofectamine 2000 reagent (Invitrogen, Carlsbad, CA, USA) according to the manufacturer's instructions.

\section{ROS determinahtion and cell viability assay}

Quantification of the ROS was performed with $10 \mu \mathrm{M}$ of CM- $\mathrm{H}_{2}$ DCFDA (Life Technologies, Eugene, OR, USA) using a BD FACSCalibur (BD Bioscience, San Jose, CA, USA). Cell viability was evaluated with a water soluble tetrazolium salt assay using an EZ-Cytox Cell Viability Assay kit (Itsbio, Seoul, Korea) according to the manufacturer's instruction. Viability was expressed as a percentage of the control group.

\section{Quantitative real-time PCR analysis}

Total RNA was isolated using RNAiso Plus (TaKaRa, Shiga, Japan), and complementary DNA was synthesized by reverse transcription using a ReverTra Ace qPCR RT kit (Toyobo, Osaka, Japan). Quantitative real-time PCR was performed to validate the expression levels of the target mRNAs using SYBR Premix Ex Taq (TaKaRa) on an ABI 7300 machine (Applied Biosystems, Carlsbad, CA, USA). The specific primers for real-time PCR include the following: HSP70 (forward primer : 5'-CGGGGTAACCGACCAATCAATCT GAAGCCATCT-3', reverse primer : 5'-GTTCAGCATCAGGGGGAT CT-3'), HSP27 (forward primer : 5'-TGACGGTCAAGACCAAGGA T-3', reverse primer : 5'-ATGGTGATCTCGTTGGACTG-3'), c-fos (forward primer : 5'-CAAGCGGAGACAGACCAACT-3', reverse primer : $5^{\prime}$ AGTCAGATCAAGGGAAGCCA- $3^{\prime}$ ) and $\beta$-actin (forward primer : 5'-AGTACTCCGTGTGGATCGGC-3', reverse primer : 5'- C CGCTCGAGCCGGTTCCCTGCTCTCTGTC- $3^{\prime}$ ). The relative values for the target mRNAs were calculated after normalization to the $\mathrm{Ct}$ value of $\beta$-actin in the same sample using the ddCt method.

\section{Confocal microscopy and immunofluorescence staining}

A172 cells were first seeded onto glass coverslips in complete medium and allowed to adhere overnight at $37^{\circ} \mathrm{C}$ before proceeding with the treatments. Cells were fixed using $4 \%$ paraformaldehyde (Biosesang, Sungnam, Korea) and incubated in $0.5 \%$ Triton X-100 for permeabilization. Then, the cells were incubated with an anti-HSF1 monoclonal antibody (1:1000, Promega). Immunoreactivity was visualized with Texas Red-conjugated anti-rabbit immunoglobulin G (Santa Cruz Biotechnology) using a Zeiss LSM 700 laser fluorescence confocal 
microscope with Zen software (Carl Zeiss Microimaging, Jena, Germany).

\section{Co-immunoprecipitation analysis}

A172 cells transfected with Myc-tagged FL-BIS or Myc-tagged $\Delta 281-$ 292 BIS were treated with $\mathrm{H}_{2} \mathrm{O}_{2}$ for $3 \mathrm{~h}$. An equal amount of each protein lysate was incubated with normal rabbit immunoglobulin $\mathrm{G}$ or antibodies against HSF1 (Cell Signaling Technology) for $4 \mathrm{~h}$ at $4{ }^{\circ} \mathrm{C}$, followed by incubation with $20 \mu \mathrm{l}$ of protein A magnetic beads (Millipore) for $16 \mathrm{~h}$ at $4{ }^{\circ} \mathrm{C}$. The immune complexes were analyzed by western blot analyses with anti-c-Myc antibodies (Santa Cruz Biotechnology). Protein lysates were also subjected to western blot analyses with the indicated antibodies.

\section{Statistics}

All experiments were repeated at least three times, and the data are shown as the mean \pm s.e. Student's $t$-tests were employed to compare two different groups. A $P$-value of $<0.05$ was considered to be statistically significant.

\section{RESULTS}

BIS mobility is reduced by $\mathrm{H}_{2} \mathrm{O}_{2}$ treatment

$\mathrm{H}_{2} \mathrm{O}_{2}$ treatment of A172 cells reduced BIS protein migration, as determined by sodium dodecyl sulfate-polyacrylamide gel electrophoresis (SDS-PAGE). This mobility shift was apparent as early as $30 \mathrm{~min}$ after treatment, with the maximum effect observed at $3 \mathrm{~h}$. Then, the mobility returned to baseline at $6 \mathrm{~h}$. At least three different protein bands were observed, indicating that $\mathrm{H}_{2} \mathrm{O}_{2}$ induced stepwise and multiple modifications of BIS in a time-dependent manner. The magnitude of the mobility shift was independent of $\mathrm{H}_{2} \mathrm{O}_{2}$ concentration (Figure 1a).
$\mathrm{H}_{2} \mathrm{O}_{2}$-induced retardation of BIS mobility was also observed in a diverse range of cell types, including A549, HK2 cells mouse embryonic fibroblasts (Figure $1 \mathrm{~b}$ ). In subsequent experiments, we used A172 cells treated with $100 \mu \mathrm{M}$ of $\mathrm{H}_{2} \mathrm{O}_{2}$ for $3 \mathrm{~h}$.

Pretreatment of the cells with the ROS scavenger N-acetyl-Lcysteine abrogated the effect of $\mathrm{H}_{2} \mathrm{O}_{2}$ on BIS electrophoretic mobility (Figure 1c). BIS expression was upregulated by heat shock, but there was no shift in mobility under these conditions (Figure 1d). These results suggest that $\mathrm{H}_{2} \mathrm{O}_{2}$ mediated ROS accumulation, and not other types of cellular stress, is responsible for the change in BIS protein mobility induced by $\mathrm{H}_{2} \mathrm{O}_{2}$.

\section{$\mathrm{H}_{2} \mathrm{O}_{2}$ induces $\mathrm{BIS}$ phosphorylation via ERK activation}

Because phosphorylation is the most common biochemical modification of proteins, we examined whether phosphorylation accounted for the heterogeneity of BIS observed in SDS-PAGE following $\mathrm{H}_{2} \mathrm{O}_{2}$ treatment. Incubation of A172 cell lysates with alkaline phosphatase completely reduced the $\mathrm{H}_{2} \mathrm{O}_{2}$ induced mobility shift of BIS (Figure 2a), suggesting that BIS phosphorylation in the presence of $\mathrm{H}_{2} \mathrm{O}_{2}$ leads to its altered mobility. To determine which kinase is responsible, we pretreated A172 cells with the inhibitors U0126 (ERK inhibitor), SB203580 (p38 inhibitor) or SP600125 (JNK inhibitor) prior to $\mathrm{H}_{2} \mathrm{O}_{2}$ exposure. U0126 completely abolished $\mathrm{H}_{2} \mathrm{O}_{2}$ induced BIS phosphorylation; however, alteration in BIS mobility was detected in A172 cells pretreated with SB203580 or SP600125 (Figure 2b), although these agents abrogated the phosphorylation of their target proteins (Figure 2c). These
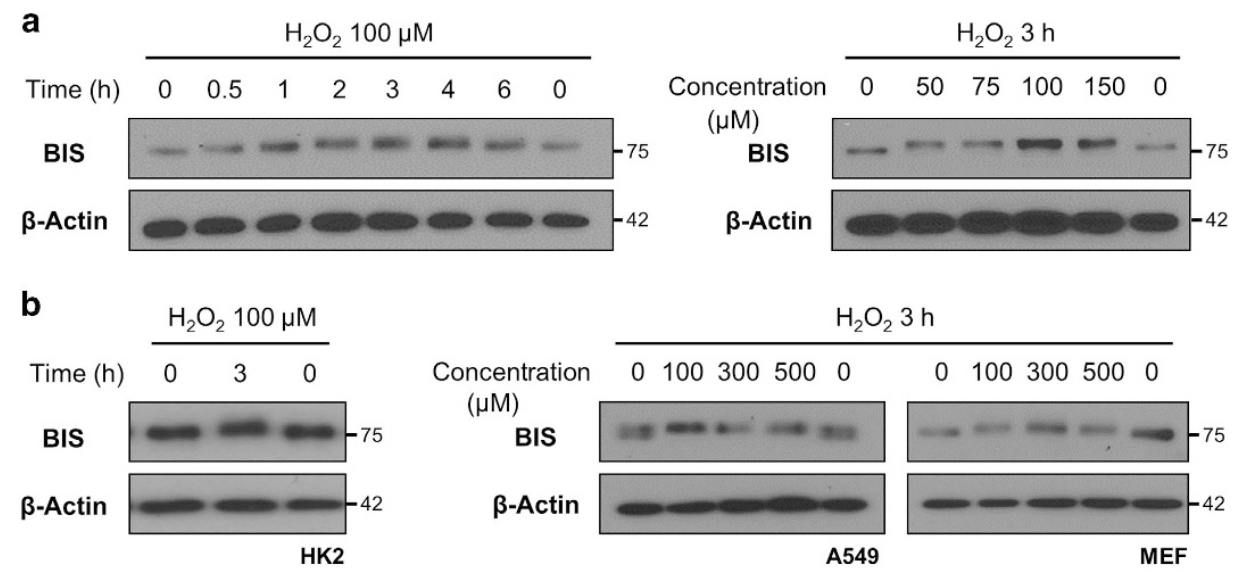

C
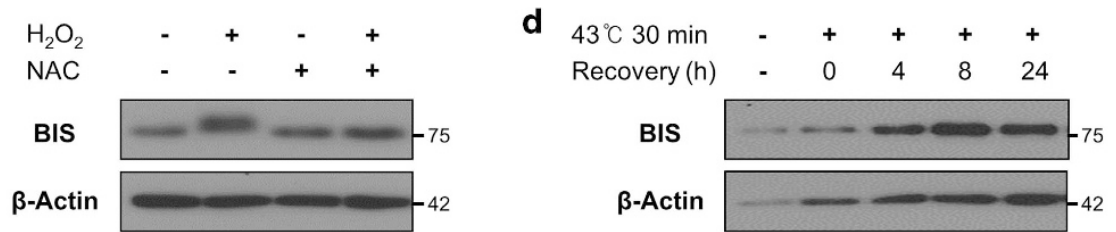

Figure $1 \mathrm{H}_{2} \mathrm{O}_{2}$-induced mobility shift of BIS visualized by electrophoresis. The BIS protein was detected by western blotting, with $\beta$-actin serving as a loading control. (a) A172, (b) HK2, A549 and MEF cells were treated with the indicated concentrations of $\mathrm{H}_{2} \mathrm{O}_{2}$ for the indicated times. (c) A172 cells were treated with $1 \mathrm{~mm} \mathrm{~N}$-acetyl-L-cysteine (NAC) for $1 \mathrm{~h}$ or were left untreated and were then exposed to $100 \mu \mathrm{m} \mathrm{H} \mathrm{H}_{2} \mathrm{O}_{2}$ for $3 \mathrm{~h}$. (d) $\mathrm{A} 172$ cells were exposed to heat shock $\left(43^{\circ} \mathrm{C}\right.$ for $30 \mathrm{~min}$ ) and then allowed to recover by incubation at $37^{\circ} \mathrm{C}$ for the indicated times. BIS, B-cell lymphoma (BCL)-2-interacting cell death suppressor; MEF, mouse embryonic fibroblasts. 
a

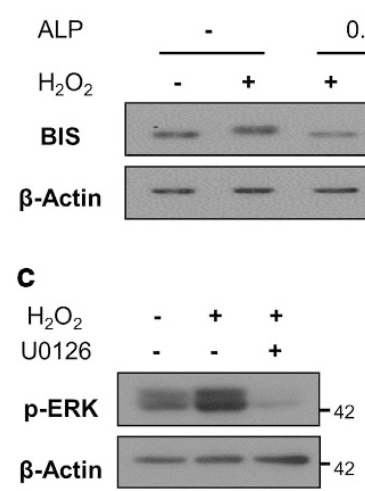

b

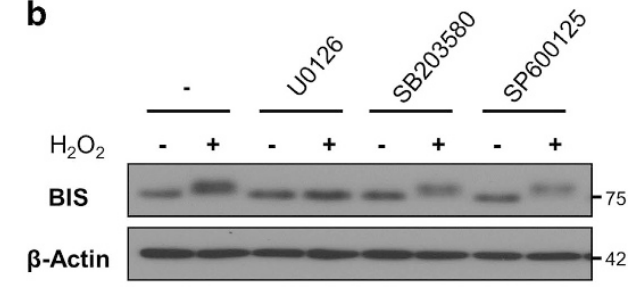

Figure 2 ERK-dependent phosphorylation of BIS following $\mathrm{H}_{2} \mathrm{O}_{2}$ treatment. Expression of indicated proteins was analyzed by western blotting, with $\beta$-actin serving as a loading control. (a) A172 cells were treated with $100 \mu \mathrm{m} \mathrm{H}_{2} \mathrm{O}_{2}$ for $3 \mathrm{~h}$, after which cells were lysed, and alkaline phosphatase $(0.5 \mathrm{U})$ was added to cell lysates, which were incubated at $37^{\circ} \mathrm{C}$ for 30 min. (b) A172 cells were treated with U0126 (ERK inhibitor), SB203580 (p38 inhibitor), or SP600125 (JNK inhibitor) for $1 \mathrm{~h}$ prior to addition of $100 \mu_{\mathrm{M} \mathrm{H}} \mathrm{H}_{2}$. After $3 \mathrm{~h}$, total protein was extracted and BIS expression was determined by western blotting. (c) Activation of ERK, p38, and JNK was suppressed by their respective inhibitors, as determined by western blotting. BIS, B-cell lymphoma (BCL)-2-interacting cell death suppressor; ERK, extracellular signaling-regulated kinase; JNK, c-Jun N-terminal kinase.

results indicate that BIS phosphorylation in the presence of $\mathrm{H}_{2} \mathrm{O}_{2}$ is ERK dependent.

\section{BIS is phosphorylated at Thr285 and Ser289 under oxidative stress conditions}

We sought to identify the BIS residues that are phosphorylated under oxidative stress conditions using immunoprecipitationcoupled liquid chromatography/tandem mass spectrometry. Immunoprecipitation and western blot analysis were carried out using an anti-BIS antibody (Figure 3a); we confirmed that the band at $\sim 70 \mathrm{kDa}$ corresponded to BIS by mass spectrometry (data not shown). Several residues of the BIS protein were phosphorylated following $\mathrm{H}_{2} \mathrm{O}_{2}$ treatment; based on this information, along with computational predictions, Thr285 and Ser289 were identified as potential ERK target sites. We also carried out a quantitative analysis based on the ion chromatogram. As expected, the unphosphorylated peptide 283-SSTPLHSPSP-292 was more abundant in the control sample, while the phosphopeptide 283-SSpTPLHpSPSP-292 was only detected in samples from the $\mathrm{H}_{2} \mathrm{O}_{2}$-treated cells (Figure 3b).

We then constructed a vector expressing recombinant human BIS with deletions in the residues Ala281 to Pro292, which encompassed the putative phosphorylation sites $(\Delta 281-$ 292 BIS; Figure 3c). A western blot analysis of $\Delta 281-292$ BIStransfected A172 cell lysates showed two separate BIS bands with high and low molecular weights corresponding to endogenous BIS and $\Delta 281-292$ BIS, respectively. Following $\mathrm{H}_{2} \mathrm{O}_{2}$ treatment, a mobility shift was detected in both bands; however, the shift was reduced for $\Delta 281-292$ BIS, as shown by the increased distance between the two bands (Figure 3d). These results indicate that the $\mathrm{H}_{2} \mathrm{O}_{2}$-induced mobility shift of $\Delta 281-292$ BIS was partly abolished by the deletion of amino acids 281-292, suggesting that Thr285 and/or Ser289 phosphorylation is responsible for the shift.

We also evaluated whether phosphorylated BIS participates in the physiological redox signaling pathway involving ERK because previous studies showed that BIS could alter the activation of ERK, which is sensitive to the redox state of the cells. ${ }^{26}$ We found that $\Delta 281-292$ BIS overexpression in A172 cells did not affect the level of phospho-ERK (p-ERK) and phospho-ETS domain-containing protein (ELK)-1 (p-ELK) proteins and the transactivation of $\mathrm{c}$-fos, which are downstream targets of ERK, following treatment with $\mathrm{H}_{2} \mathrm{O}_{2}$ (Figures 3d and e).

\section{Deletion of BIS residues 281-292 sensitizes A172 cells to $\mathrm{H}_{2} \mathrm{O}_{2}$-induced cell death}

To determine the physiological significance of BIS phosphorylation under oxidative stress conditions, we evaluated the effects of $\Delta 281-292$ BIS on cell viability after $\mathrm{H}_{2} \mathrm{O}_{2}$ exposure. A172 cells transfected with the various constructs were exposed to $100 \mu \mathrm{M} \mathrm{H}_{2} \mathrm{O}_{2}$ for $3 \mathrm{~h}$, and viability was assessed with water soluble tetrazolium salt assays. Overexpression of FL-BIS or $\Delta 281-292$ BIS had no effect on the basal level of A172 cell viability, whereas viability was decreased to $71.1 \%, 83.9 \%$ and $60.3 \%$ in the cells transfected with the empty vector, FL-BIS, and $\Delta 281-292$ BIS, respectively, after $\mathrm{H}_{2} \mathrm{O}_{2}$ exposure (Figure 4a). These results show that the susceptibility to $\mathrm{H}_{2} \mathrm{O}_{2}$-induced cell death was decreased by FL-BIS overexpression and increased by $\Delta 281-292$ BIS overexpression $\left(P=0.0459\right.$ and 0.0217 vs $\mathrm{H}_{2} \mathrm{O}_{2}$-treated empty vectortransfected cells).

To determine whether the sensitization resulting from deletion of residues 281-292 is due to a loss of anti-oxidant capacity, ${ }^{20}$ we measured ROS accumulation in FL-BIS- and 4281-292 BIS-transfected A172 cells following $\mathrm{H}_{2} \mathrm{O}_{2}$ treatment 
a

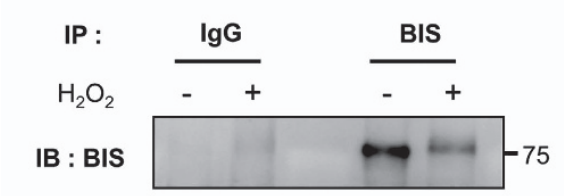

c

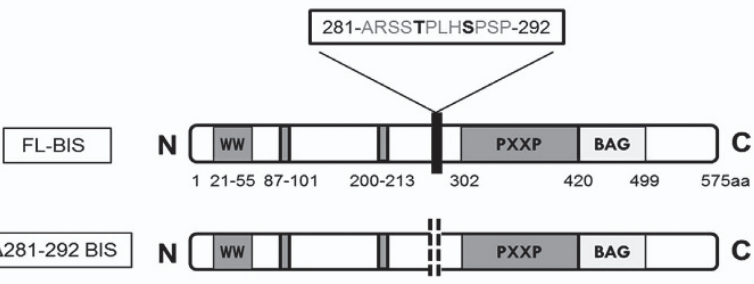

b

283-SSTPLHSPSP-292

283-SSpTPLHpSPSP-292
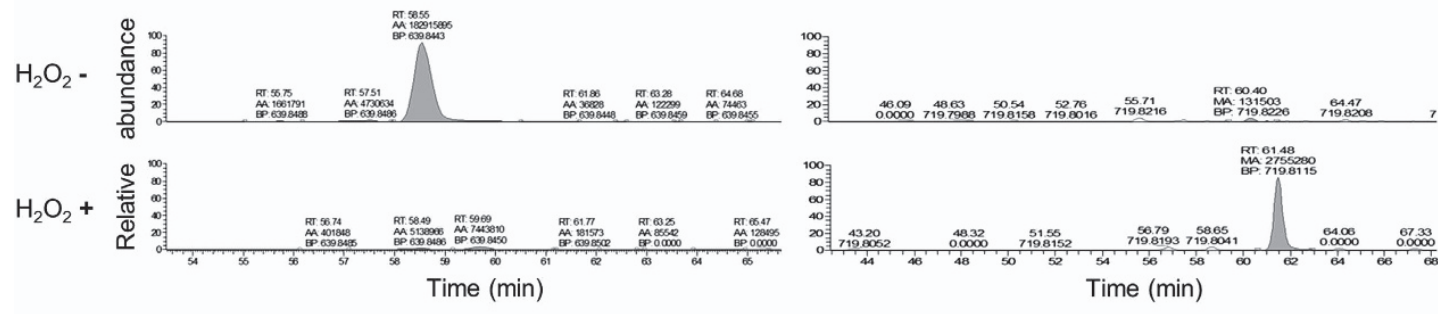

d
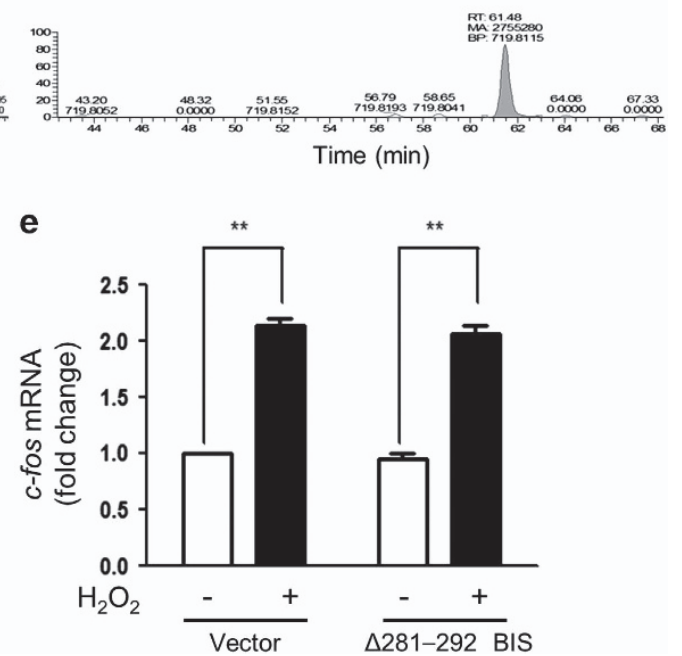

Figure 3 Identification of BIS residues phosphorylated under oxidative stress. (a, b) Immunoprecipitation coupled with liquid chromatography/tandem mass spectrometry (LC-MS/MS) was used to identify BIS phosphorylation sites following $\mathrm{H}_{2} \mathrm{O}_{2}$ treatment. A172 cells were treated with $100 \mu \mathrm{M} \mathrm{H}_{2} \mathrm{O}_{2}$ for $3 \mathrm{~h}$, and the BIS protein was immunoprecipitated from cell lysates with an anti-BIS antibody. (a) An aliquot of the immunoprecipitated proteins was analyzed by western blotting using an anti-BIS antibody. (b) The band corresponding to BIS in the immunoprecipitated complex was subjected to trypsin digestion and analyzed by LC-MS/MS; data were compared to computational predictions. The abundance of the unphosphorylated peptide 283-SSTPLHSPSP-292 and the phosphopeptide 283SSpTPLHpSPSP-292 was quantified by peak area integration using the extracted ion chromatograms. (c) Schematic representation of FLBIS and mutant BIS (with deletion of residues Ala281 to Pro292; $\Delta 281-292$ BIS). (d) A172 cells were transfected with the pCAGGS vector (Vector) or $\Delta 281-292 \mathrm{BIS}$ and treated $48 \mathrm{~h}$ later with $100 \mu \mathrm{m} \mathrm{H}_{2} \mathrm{O}_{2}$ for $3 \mathrm{~h}$. Cell lysates were subjected to western blotting to assess the levels of BIS, p-ERK, and p-ELK proteins, with $\beta$-actin used as a loading control. (e) Relative levels of $c$-fos mRNA were evaluated by quantitative real-time PCR. Values represent the mean \pm s.e. of triplicate experiments. ${ }^{*} P<0.05,{ }^{*} P<0.01$. BIS, B-cell lymphoma (BCL)-2-interacting cell death suppressor; ERK, extracellular signaling-regulated kinase; ELK, ETS domain-containing protein; $\mathrm{FL}$, full length.

by flow cytometry. There was no difference between the two proteins in ROS levels, which were increased by $\sim 1.7$-fold $(P<0.001)$ in cells overexpressing either protein following treatment with $100 \mu \mathrm{M}$ of $\mathrm{H}_{2} \mathrm{O}_{2}$ for $3 \mathrm{~h}$ (Figure $4 \mathrm{~b}$ ). Taken together, these results suggest that overexpression of $\Delta 281-292$ BIS increases sensitivity to ROS without affecting intracellular ROS production and activation of the ERK-ELK-c-fos pathway induced by $\mathrm{H}_{2} \mathrm{O}_{2}$.

\section{Deletion of BIS residues 281-292 causes downregulation of} HSP70 after $\mathrm{H}_{2} \mathrm{O}_{2}$ treatment

Several studies have shown that HSP70, a BIS binding partner, has a protective function as a chaperone protein under oxidative stress conditions. ${ }^{27,28}$ Given the decrease in cell viability induced by $\mathrm{H}_{2} \mathrm{O}_{2}$ upon deletion of BIS residues 281292, we hypothesized that HSP70 along with BIS protects against $\mathrm{H}_{2} \mathrm{O}_{2}$. HSP70 levels were unaffected by $\mathrm{H}_{2} \mathrm{O}_{2}$ treatment in cells overexpressing the empty vector or FL-BIS; however, in $\Delta 281-292$ BIS-transfected cells, HSP70 expression was reduced under oxidative stress conditions. A quantitative analysis revealed that the HSP70 protein level was decreased by 19.6\% $(P=0.0111)$ in cells expressing the BIS deletion mutant following $\mathrm{H}_{2} \mathrm{O}_{2}$ treatment but remained constant in the other groups (Figure $4 \mathrm{c}$ ). Similar trends were observed by quantitative reverse transcriptase-PCR analysis; HSP70 mRNA levels were reduced by $45.3 \% \quad(P=0.0312)$ in $\Delta 281-292$ BIStransfected cells exposed to $\mathrm{H}_{2} \mathrm{O}_{2}$ but were unchanged in the other groups (Figure 4d). However, HSP27 mRNA levels were 
a

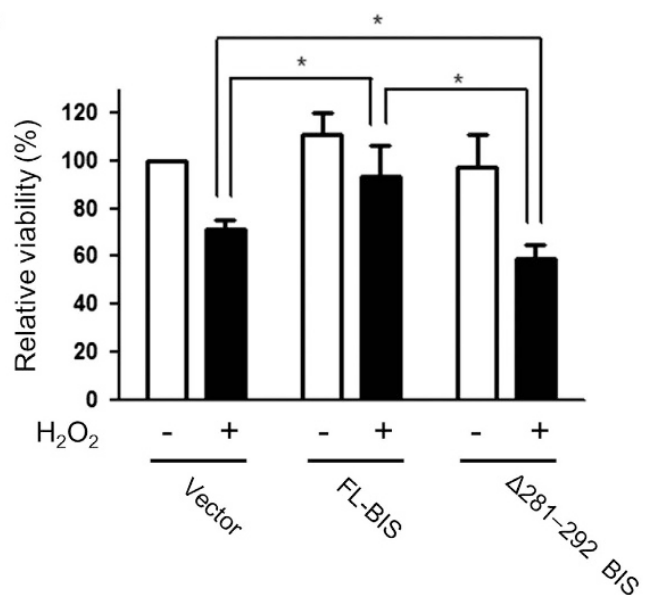

c

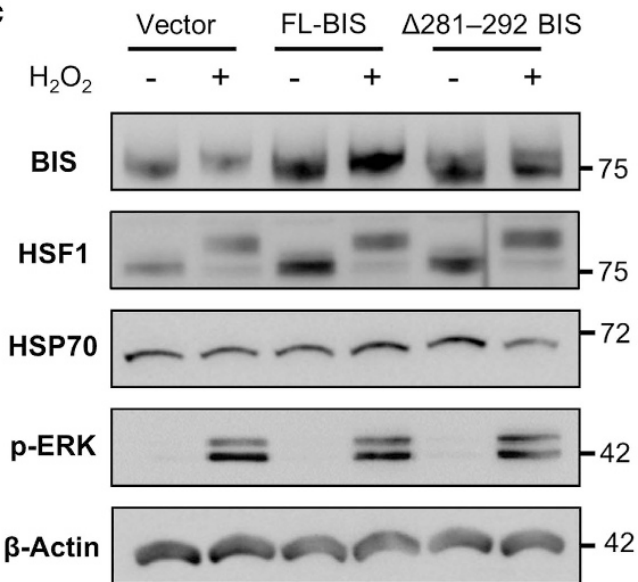

d

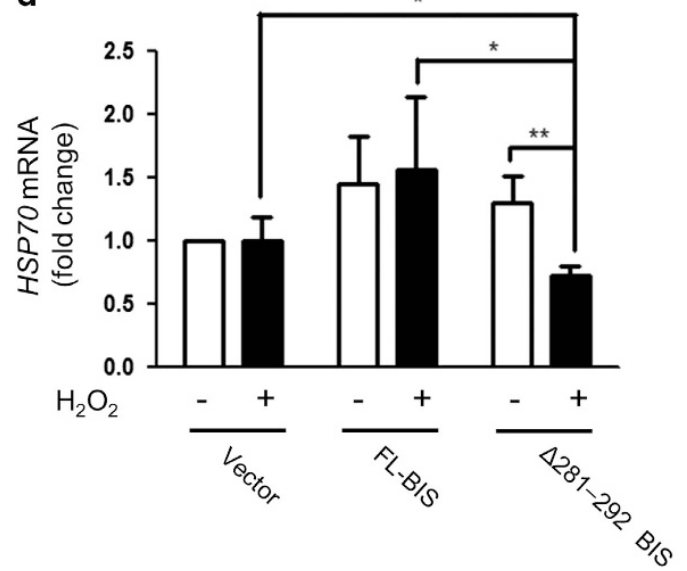

b
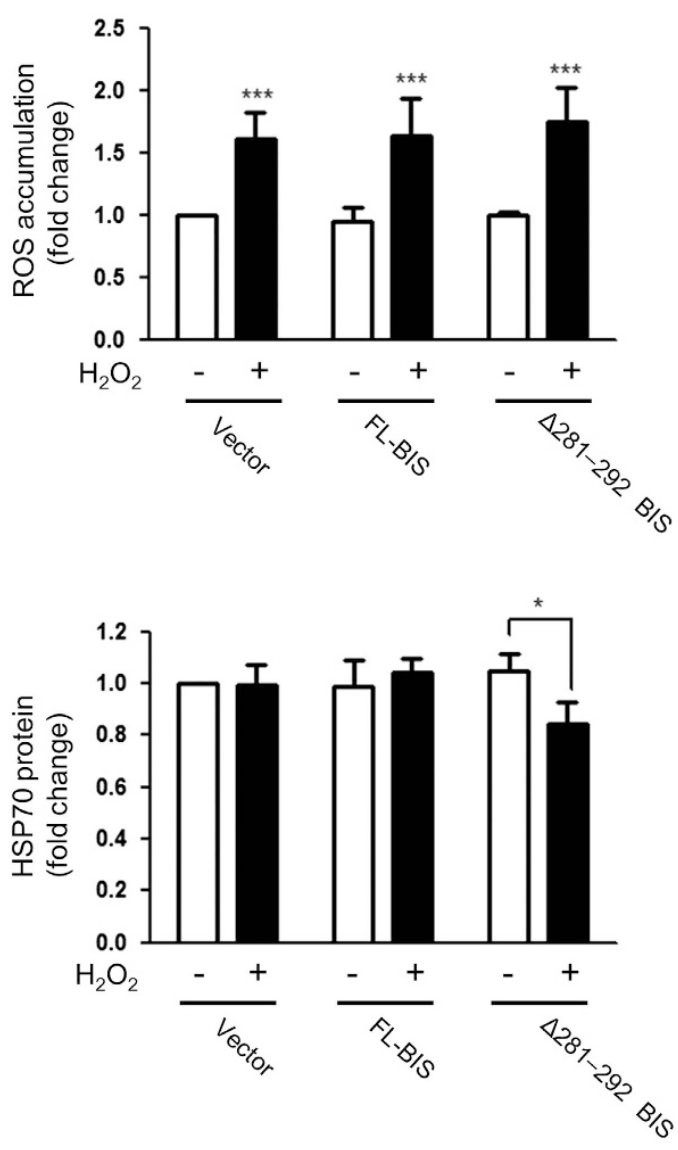

e

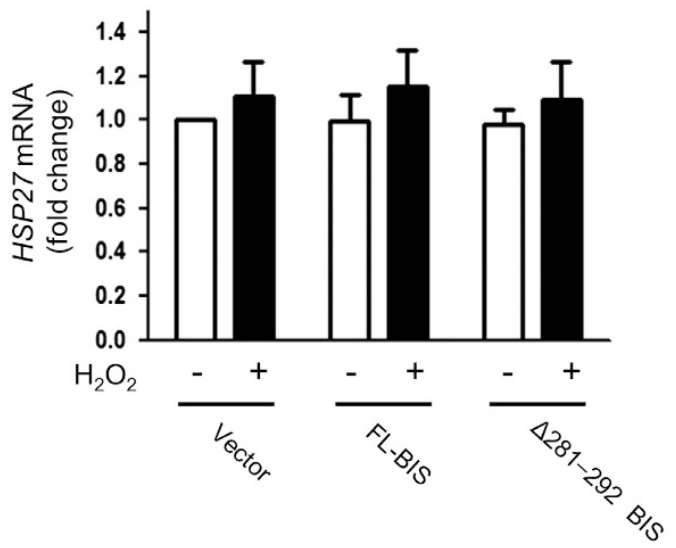

Figure 4 Effect of $\Delta 281-292$ BIS overexpression on cell viability and HSP70 expression following $\mathrm{H}_{2} \mathrm{O}_{2}$ treatment. A172 cells were transfected with pCAGGS (Vector), FL-BIS, or $\Delta 281-292 \mathrm{BIS}$ and then treated $48 \mathrm{~h}$ later with $100 \mu \mathrm{m} \mathrm{H}_{2} \mathrm{O}_{2}$ for $3 \mathrm{~h}$. (a) Cell viability was determined with the water soluble tetrazolium salt assay; viability of cells transfected with the empty vector was designated as $100 \%$. Values represent the mean \pm s.e. of triplicate experiments. ${ }^{*} P<0.05$. (b) Intracellular ROS levels were assessed by $\mathrm{CM}-\mathrm{H}_{2} \mathrm{DCFDA}$ staining and flow cytometry. Data are presented as the fold change in the mean value from three independent experiments with the s.e. $* * * P<0.001$ vs untreated cells (c) Expression levels of BIS, HSP70, HSF1, and p-ERK were determined by western blotting (left panels). The results from a densitometric analysis of HSP70 protein levels from three independent experiments are shown in the right panels. The basal level of HSP70 protein in A172 cells transfected with the vector was arbitrarily set to 1. Relative levels of (d) HSP70 mRNA and (e) HSP27 mRNA were evaluated by quantitative real-time PCR. Values represent the mean \pm s.e. of triplicate experiments. ${ }^{*} P<0.05$, ${ }^{*} P<0.01$. BIS, B-cell lymphoma (BCL)-2-interacting cell death suppressor; ERK, extracellular signaling-regulated kinase; HSF1, heat shock transcription factor 1 ; HSP70, heat shock protein 70; ROS, reactive oxygen species. 

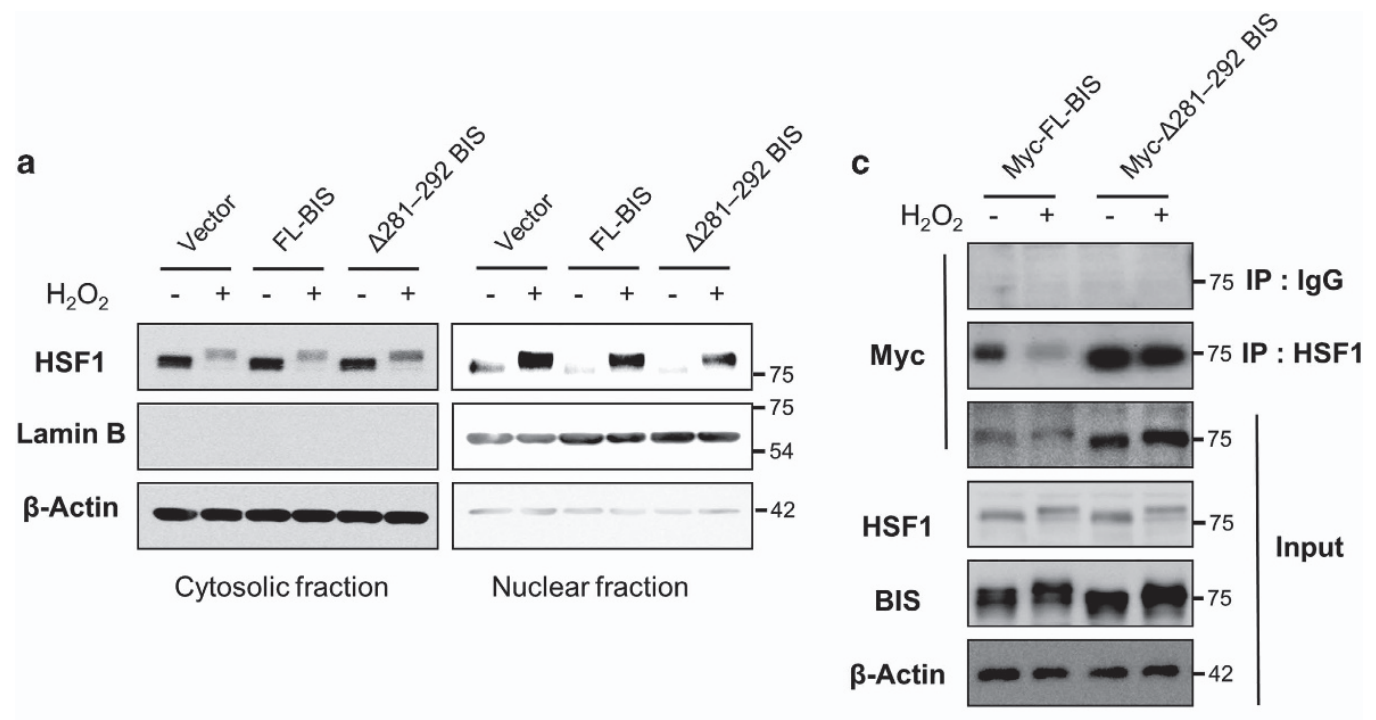

b

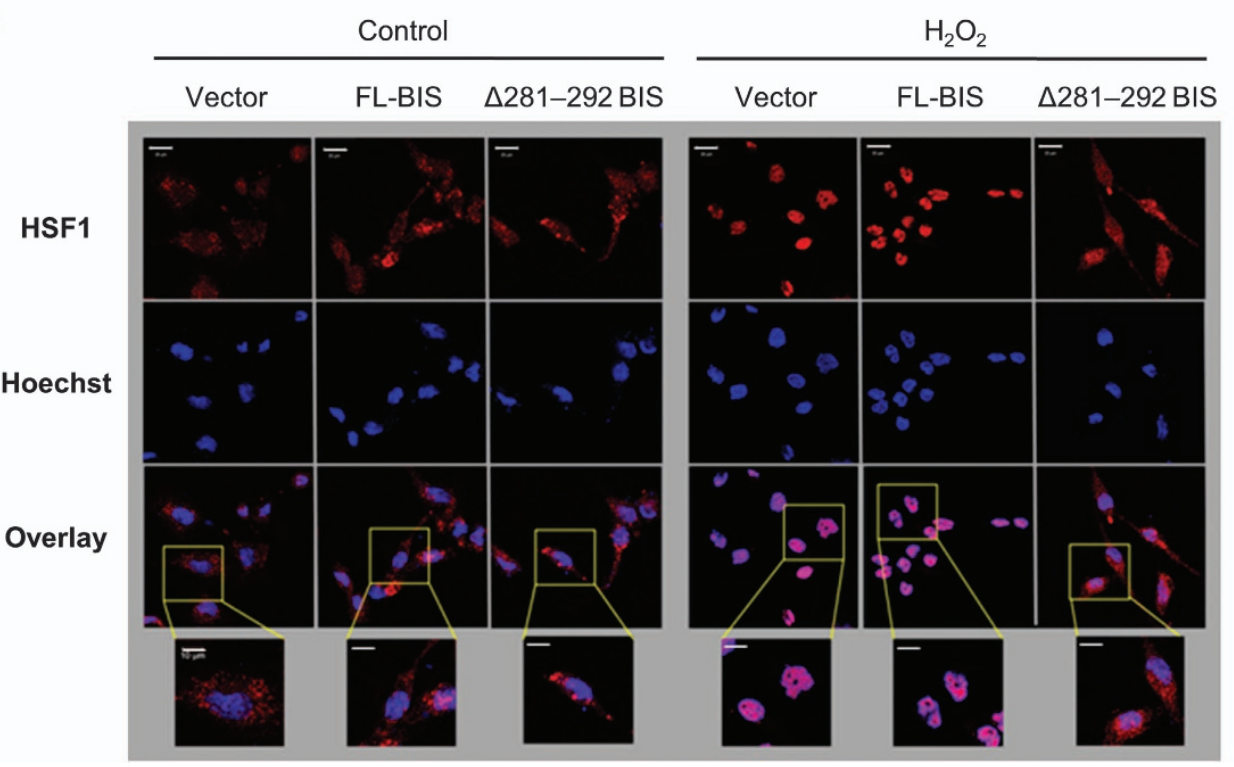

Figure 5 Effect of the BIS mutation ( $\Delta 281-292)$ on HSF1 nuclear translocation. A172 cells were treated with $100 \mu \mathrm{m} \mathrm{H}_{2} \mathrm{O}_{2}$ for $3 \mathrm{~h}$ at $48 \mathrm{~h}$ after transfection of the indicated constructs. (a) Cytoplasmic and nuclear fractions were prepared, and BIS and HSF1 levels were detected by western blotting, with $\beta$-Actin and Lamin B used as loading controls. (b) The subcellular localization of HSF1 was visualized by confocal microscopy. For immunolabeling, cells were incubated with a primary antibody against HSF1 followed by a Texas Redconjugated secondary antibody. Nuclei were stained with Hoechst. Bar $=20 \mu \mathrm{m}$. Higher magnifications of the selected areas from overlay images are also provided. Bar $=10 \mu \mathrm{m}$. (c) The interaction of BIS and HSF1 was verified by co-immunoprecipitation analysis after transfection of Myc-tagged-FL-BIS, or Myc-tagged- $\Delta 281-292 \mathrm{BIS}$. Following exposure to $\mathrm{H}_{2} \mathrm{O}_{2}$, the cell lysates were immunoprecipitated with normal rabbit immunoglobulin G or anti-HSF1 antibody, followed by immunoblotting with an anti-Myc antibody. Total protein lysates were also subjected to western blot analyses with the indicated antibodies. BIS, B-cell lymphoma (BCL)-2-interacting cell death suppressor; HSF1, heat shock transcription factor 1.

not significantly different among the three groups (Figure 4e). Taken together, these data demonstrate that blocking ERK-dependent BIS phosphorylation specifically suppresses HSP70 transcription under oxidative stress conditions.

\section{Deletion of BIS residues 281-292 blocks nuclear translocation of HSF1}

To determine whether BIS regulates HSP70 transactivation following $\mathrm{H}_{2} \mathrm{O}_{2}$ exposure, we assessed whether $\Delta 281-292$ BIS overexpression affects the activation of HSF1, a regulator of HSP70 transcription, in a process involving hyperphosphorylation, shuttling from the cytoplasm to the nucleus, and binding to target gene promoters. ${ }^{29-31}$ We found that $\Delta 281-292$ BIS overexpression in A172 cells had no effect on the HSF1 protein level or phosphorylation status (Figure 4c). However, the level of HSF1 in the nuclear fraction was reduced in these cells compared to those expressing the empty vector or FL-BIS, in which $\mathrm{H}_{2} \mathrm{O}_{2}$ treatment induced nuclear translocation 
(Figure 5a). An immunocytochemical analysis revealed that $\Delta$ 281-292 BIS-transfected cells showed impaired nuclear translocation of HSF1 after $\mathrm{H}_{2} \mathrm{O}_{2}$ treatment (Figure 5b). Then, we determined whether $\mathrm{H}_{2} \mathrm{O}_{2}$-induced BIS phosphorylation affected the interactions between BIS and HSF1 proteins. As shown in Figure $5 \mathrm{c}$, without $\mathrm{H}_{2} \mathrm{O}_{2}$ treatment, both the FL-BIS and $\Delta 281-292$ BIS proteins were detected as a complex with HSF1. However, following $\mathrm{H}_{2} \mathrm{O}_{2}$ treatment, the interaction strength between wild-type BIS and HSF1 was notably reduced, whereas the binding affinity between $\Delta 281-292$ BIS and HSF1 was not changed. These findings clearly indicate that the phosphorylation status of BIS is critical in determining the efficiency of its interaction with HSF1, which affects the subcellular localization of HSF1.

\section{DISCUSSION}

BIS has been implicated in various cellular processes; however, little is known about the biological consequences of BIS protein modification. The present study demonstrated that $\mathrm{H}_{2} \mathrm{O}_{2}$ treatment induced ERK-dependent BIS phosphorylation. Deletion of 12 amino acids $(\Delta 281-292)$ in the protein, including the potential phosphorylation sites Thr285 and Ser289, increased the sensitivity of $\mathrm{A} 172$ cells to $\mathrm{H}_{2} \mathrm{O}_{2}$-induced cell death. This is consistent with the effect of BIS knockdown on glioma or renal cell survival under oxidative stress induced by oxygen-glucose deprivation or high glucose, respectively. ${ }^{20,21}$ ERK is activated by ROS in a variety of cell types, but the precise role of the ROS-ERK pathway is a matter of debate. Several studies have reported that ERK induces apoptosis under oxidative stress conditions, ${ }^{32-34}$ while others have shown sensitization of cells to ROS following ERK inhibition or downregulation. ${ }^{35-37}$ Our findings suggest that ERK-dependent phosphorylation of BIS protects against oxidative stress, consistent with the pro-survival function of ERK. The current study is the first to report an association between biochemical modification of BIS via ERK activation and its biological activity under oxidative stress conditions. However, the partial restoration of the $\Delta 281-292$ BIS mobility shift suggests the presence of other phosphorylation sites in addition to Thr285 and Ser289 that are involved in the cellular response to oxidative stress.

The interaction between BIS and ERK has been previously demonstrated in studies that predominantly focused on the regulatory role of BIS in ERK activation. BIS is required for the interaction between ERK and its phosphatase, dual specificity phosphatase 6, while BIS depletion resulted in sustained ERK activation and inhibited angiogenesis in human umbilical vein endothelial cells. ${ }^{38}$ However, BIS was shown to promote ERKmediated pro-survival signaling by stabilizing major vault protein, thereby conferring resistance to adriamycin-induced apoptosis. ${ }^{39}$ While previous studies have demonstrated that ERK activity is modulated by BIS under different conditions, our results revealed that $\mathrm{H}_{2} \mathrm{O}_{2}$-mediated activation of the ERKELK-c-fos pathway was not affected by the wild-type BIS or by the $\Delta$ 281-292 deletion mutant (Figures $3 \mathrm{~d}$ and e). Thus, phosphorylation of BIS may not be involved in the redox signal involving ERK under oxidative stress. We instead found that ROS-mediated ERK activation was critical for BIS phosphorylation, which in turn promotes cell survival. Thus, the outcome of the BIS/ERK interaction depends on the cellular context and the nature of the stressor.

HSP70 and other heat-inducible chaperone molecules protect against oxidative stress as well as heat shock stress. ${ }^{40-42}$ Considering that oxidative modifications of amino acid side chains frequently led to conformational changes and subsequent aggregation of proteins, ${ }^{43,44}$ the chaperone function of HSP70 may be critical to ensure proper folding or to prevent aggregation of client proteins in a pro-oxidative milieu, as shown in GAPDH. ${ }^{28}$ However, it has been clearly demonstrated that the $\mathrm{C}$ terminus of HSP70-interacting protein facilitates proteasomal degradation of oxidized proteins. ${ }^{45,46}$ Thus, under oxidative stress, the verification of chaperones and co-chaperones was critical to relieve cells from conformational stress or from the excess burdens of misfolded proteins against oxidative stress-induced cell death. Our results showed that cells overexpressing $\Delta 281-292$ BIS showed a decrease in HSP70 levels, which was accompanied by the inhibition of HSF1 nuclear translocation. We, therefore, speculated that the suppression of HSP70 expression resulting from the inhibition of HSF1 nuclear translocation might contribute, at least in part, to increasing the sensitivity to oxidative stress exhibited by cells expressing $\Delta 281-292$ BIS.

HSF1 activates BIS gene transcription by binding heat shock elements in the promoter region in response to various stimuli, including heat shock and proteasome inhibition. ${ }^{11,47}$ However, a proteomic analysis based on quantitative immunoprecipitation combined with gene knockdown demonstrated a direct interaction between the HSF1 and BIS proteins. ${ }^{48}$ Our results using co-immunoprecipitation assays clearly showed that exogenously expressed wild-type BIS as well as the $\Delta 281-292$ BIS proteins could be detected in a complex with HSF1. Interestingly, while the interaction between wild-type BIS and HSF1 was weaker after $\mathrm{H}_{2} \mathrm{O}_{2}$ treatment, the association between $\Delta 281-292$ BIS and HSF1 was not apparently changed by oxidative stress (Figure $5 \mathrm{c}$ ). These findings suggest that BIS Thr285 and/or Ser289 phosphorylation following $\mathrm{H}_{2} \mathrm{O}_{2}$ treatment may decrease the binding affinity between BIS and HSF1 and/or another interaction partner, releasing HSF1 for nuclear translocation. The loss of these phosphorylation sites on BIS may promote the persistent sequestration of HSF1, preventing the nuclear translocation and subsequent activation of target genes. Thus, phosphorylation of BIS may modulate the interaction affinity with HSF1 by which BIS modulates HSF1 activity under oxidative stress. A recent study also showed that BIS may have a key role in the nucleocytoplasmic shuttling of HSF1 under heat stress. ${ }^{49}$ However, based on the observation that heat shock did not induce BIS phosphorylation in our study, an alternative mechanism could regulate the localization of HSF1 based on cellular stress.

Although we observed inhibition of HSF1 nuclear translocation in parallel with a reduction in HSP70 levels in $\Delta 281-292$ BIS-expressing cells, HSP70 was not induced by $\mathrm{H}_{2} \mathrm{O}_{2}$ 
treatment in cells transfected with the empty vector or the wild-type BIS-expressing vector, whereas HSF1 was activated, as shown by its phosphorylation and nuclear translocation (Figure 4c). HSF1 activation is critical for the induction of HSPs in response to a variety of cellular stressors, including heat shock, oxidative stress, infection and inflammation, ${ }^{31}$ although several investigators have reported that HSF1 activation by some oxidants is not always accompanied by HSP70 upregulation. $^{50-52}$ An earlier study showed that oxidizing agents exert dual effects on the regulation of HSF1 in vitrothat is, they promote its nuclear translocation but also decrease its DNA-binding activity. ${ }^{53}$ Furthermore, $\mathrm{H}_{2} \mathrm{O}_{2}$ treatment resulted in rapid, global, but transient repression of transcription via phosphorylation and ubiquitination of RNA polymerase II. ${ }^{29}$ Thus, total HSP70 mRNA levels could be determined by the multistep activation of HSF1 and transient suppression of the transcriptional machinery upon oxidative stress, which may be different with classical heat shock stress responses. In addition, HSP27 induction was not affected by the phosphorylation status of BIS (Figure 4d), indicating that the specificity of HSF1 as a transcriptional regulator is not equivalent against target genes, which is supported by previous studies showing that HSP27 induction is not necessarily associated with HSP70 induction under various types of cellular stresses. ${ }^{54,55}$ Although phosphorylated BIS was shown to positively regulate HSF1 translocation as well as transactivation, a more detailed investigation is required to clarify the mechanism by which biochemical modification of BIS influences constitutive or inducible expression and activity of HSP70.

In this study, we demonstrated that $\mathrm{H}_{2} \mathrm{O}_{2}$ induces BIS phosphorylation via ERK, which has a role in the regulation of HSF1 nuclear translocation likely by altering its binding affinity with HSF1. However, the details of how BIS post-translational modification affects its pro-survival activity via protein-protein interactions remain to be determined.

\section{CONFLICT OF INTEREST}

The authors declare no conflict of interest.

\section{ACKNOWLEDGEMENTS}

We thank Mr. Jae-Il Kim for his technical assistance with our experiments. This research was supported by Basic Science Research Programs through the National Research Foundation of Korea (NRF) funded by the Ministry of Education, Science and Technology (2012R1A5A2047939 and 2013R1A1A2009622).

1 Lee JH, Takahashi T, Yasuhara N, Inazawa J, Kamada S, Tsujimoto Y. Bis, a $\mathrm{Bcl}-2$-binding protein that synergizes with $\mathrm{Bcl}-2$ in preventing cell death. Oncogene 1999; 18: 6183-6190.

2 Jacobs AT, Marnett LJ. HSF1-mediated BAG3 expression attenuates apoptosis in 4-hydroxynonenal-treated colon cancer cells via stabilization of anti-apoptotic Bcl-2 proteins. J Biol Chem 2009; 284: 9176-9183.

3 Wang $H Q$, Liu BQ, Gao YY, Meng X, Guan Y, Zhang HY et al. Inhibition of the JNK signalling pathway enhances proteasome inhibitor-induced apoptosis of kidney cancer cells by suppression of BAG3 expression. Br J Pharmacol 2009; 158: 1405-1412.
4 Festa M, Del Valle L, Khalili K, Franco R, Scognamiglio G, Graziano V et al. BAG3 protein is overexpressed in human glioblastoma and is a potential target for therapy. Am J Pathol 2011; 178: 2504-2512.

5 Romano MF, Festa M, Pagliuca G, Lerose R, Bisogni R, Chiurazzi F et al. BAG3 protein controls B-chronic lymphocytic leukaemia cell apoptosis. Cell Death Differ 2003; 10: 383-385.

6 Liao Q, Ozawa F, Friess H, Zimmermann A, Takayama S, Reed JC et al. The anti-apoptotic protein BAG-3 is overexpressed in pancreatic cancer and induced by heat stress in pancreatic cancer cell lines. FEBS Lett 2001; 503: 151-157.

7 Franco R, Scognamiglio G, Salerno V, Sebastiani A, Cennamo G, Ascierto PA et al. Expression of the anti-apoptotic protein BAG3 in human melanomas. J Invest Dermatol 2012; 132: 252-254.

8 Chiappetta G, Ammirante M, Basile A, Rosati A, Festa M, Monaco M et al. The antiapoptotic protein BAG3 is expressed in thyroid carcinomas and modulates apoptosis mediated by tumor necrosis factor-related apoptosisinducing ligand. J Clin Endocrinol Metab 2007; 92: 1159-1163.

9 Rosati A, Ammirante M, Gentilella A, Basile A, Festa M, Pascale M et al. Apoptosis inhibition in cancer cells: a novel molecular pathway that involves BAG3 protein. Int J Biochem Cell Biol 2007; 39: 1337-1342.

10 Pagliuca MG, Lerose R, Cigliano S, Leone A. Regulation by heavy metals and temperature of the human BAG-3 gene, a modulator of Hsp70 activity. FEBS Lett 2003; 541: 11-15.

11 Franceschelli S, Rosati A, Lerose R, De Nicola S, Turco MC, Pascale M. Bag3 gene expression is regulated by heat shock factor 1 . J Cell Physiol 2008; 215: 575-577

12 Yoo HJ, Im CN, Youn DY, Yun HH, Lee JH. Bis is Induced by Oxidative Stress via Activation of HSF1. Korean J Physiol Pharmacol 2014; 18: 403-409.

13 Christians ES, Ishiwata T, Benjamin IJ. Small heat shock proteins in redox metabolism: implications for cardiovascular diseases. Int J Biochem Cell Biol 2012; 44: 1632-1645.

14 Doong H, Price J, Kim YS, Gasbarre C, Probst J, Liotta LA et al. CAIR-1/ BAG-3 forms an EGF-regulated ternary complex with phospholipase C-gamma and Hsp70/Hsc70. Oncogene 2000; 19: 4385-4395.

15 Fuchs M, Poirier DJ, Seguin SJ, Lambert H, Carra S, Charette SJ et al. Identification of the key structural motifs involved in HspB8/HspB6-Bag3 interaction. Biochem J 2010; 425: 245-255.

16 Xu Z, Graham K, Foote M, Liang F, Rizkallah R, Hurt M et al. 14-3-3 protein targets misfolded chaperone-associated proteins to aggresomes. J Cell Sci 2013; 126: 4173-4186.

17 Li N, Du ZX, Zong ZH, Liu BQ, Li C, Zhang Q et al. PKCdelta-mediated phosphorylation of BAG3 at Ser187 site induces epithelial-mesenchymal transition and enhances invasiveness in thyroid cancer FRO cells. Oncogene 2013; 32: 4539-4548.

18 lorio V, Festa M, Rosati A, Hahne M, Tiberti C, Capunzo M et al. BAG3 regulates formation of the SNARE complex and insulin secretion. Cell Death Dis 2015; 6: e1684.

19 Lee MY, Kim SY, Shin SL, Choi YS, Lee JH, Tsujimoto Y et al. Reactive astrocytes express bis, a bcl-2-binding protein, after transient forebrain ischemia. Exp Neurol 2002; 175: 338-346.

20 Jung SE, Kim YK, Youn DY, Lim MH, Ko JH, Ahn YS et al. Downmodulation of Bis sensitizes cell death in $\mathrm{C} 6$ glioma cells induced by oxygen-glucose deprivation. Brain Res 2010; 1349: 1-10.

$21 \mathrm{Lim}$ JH, Youn DY, Yoo HJ, Yoon HH, Kim MY, Chung S et al. Aggravation of diabetic nephropathy in BCL-2 interacting cell death suppressor (BIS)haploinsufficient mice together with impaired induction of superoxide dismutase (SOD) activity. Diabetologia 2014; 57: 214-223.

22 Youn DY, Lee DH, Lim MH, Yoon JS, Lim JH, Jung SE et al. Bis deficiency results in early lethality with metabolic deterioration and involution of spleen and thymus. Am J Physiol Endocrinol Metab 2008; 295: E1349-E1357.

23 Cui MN, Yun HH, Lee NE, Kim HY, Im CN, Kim YS et al. Depletion of BIS sensitizes A549 cells to treatment with cisplatin. Mol Cell Toxicol 2016; 12: 63-71.

24 Obenauer JC, Cantley LC, Yaffe MB. Scansite 2.0: proteome-wide prediction of cell signaling interactions using short sequence motifs. Nucleic Acids Res 2003; 31: 3635-3641.

25 Xue Y, Ren J, Gao X, Jin C, Wen L, Yao X. GPS 2.0, a tool to predict kinase-specific phosphorylation sites in hierarchy. Mol Cell Proteomics 2008; 7: 1598-1608.

26 Torres M, Forman HJ. Redox signaling and the MAP kinase pathways. Biofactors 2003; 17: 287-296. 
27 Leung AM, Redlak MJ, Miller TA. Role of heat shock proteins in oxygen radical-induced gastric apoptosis. J Surg Res 2015; 193: 135-144.

28 Lazarev VF, Nikotina AD, Mikhaylova ER, Nudler E, Polonik SG, Guzhova IV et al. Hsp70 chaperone rescues $\mathrm{C} 6$ rat glioblastoma cells from oxidative stress by sequestration of aggregating GAPDH. Biochem Biophys Res Commun 2016; 470: 766-771.

29 Vihervaara A, Sistonen L. HSF1 at a glance. J Cell Sci 2014; 127: 261-266.

30 Anckar J, Sistonen L. Regulation of HSF1 function in the heat stress response: implications in aging and disease. Annu Rev Biochem 2011; 80: 1089-1115.

31 Calderwood SK, Xie Y, Wang X, Khaleque MA, Chou SD, Murshid A et al. Signal transduction pathways leading to heat shock transcription. Sign Transduct Insights 2010; 2: 13-24.

32 Petrache I, Choi ME, Otterbein LE, Chin BY, Mantell LL, Horowitz S et al. Mitogen-activated protein kinase pathway mediates hyperoxia-induced apoptosis in cultured macrophage cells. Am J Physiol 1999; 277: L589-L595.

33 Bhat NR, Zhang P. Hydrogen peroxide activation of multiple mitogenactivated protein kinases in an oligodendrocyte cell line: role of extracellular signal-regulated kinase in hydrogen peroxide-induced cell death. J Neurochem 1999; 72: 112-119.

34 Ishikawa Y, Kitamura M. Anti-apoptotic effect of quercetin: intervention in the JNK- and ERK-mediated apoptotic pathways. Kidney Int 2000; 58: 1078-1087.

35 Guyton KZ, Liu Y, Gorospe M, Xu Q, Holbrook NJ. Activation of mitogenactivated protein kinase by $\mathrm{H} 2 \mathrm{O} 2$. Role in cell survival following oxidant injury. J Biol Chem 1996; 271: 4138-4142.

36 Aikawa R, Komuro I, Yamazaki T, Zou Y, Kudoh S, Tanaka M et al. Oxidative stress activates extracellular signal-regulated kinases through Src and Ras in cultured cardiac myocytes of neonatal rats. J Clin Invest 1997; 100: 1813-1821.

37 Ikeyama S, Kokkonen G, Shack S, Wang XT, Holbrook NJ. Loss in oxidative stress tolerance with aging linked to reduced extracellular signal-regulated kinase and Akt kinase activities. FASEB J 2002; 16: 114-116.

38 Falco A, Festa M, Basile A, Rosati A, Pascale M, Florenzano F et al. BAG3 controls angiogenesis through regulation of ERK phosphorylation. Oncogene 2012; 31: 5153-5161.

39 Pasillas MP, Shields S, Reilly R, Strnadel J, Behl C, Park R et al. Proteomic analysis reveals a role for $\mathrm{Bcl} 2$-associated athanogene 3 and major vault protein in resistance to apoptosis in senescent cells by regulating ERK $1 / 2$ activation. Mol Cell Proteomics 2015; 14: 1-14.

40 Oksala NK, Ekmekci FG, Ozsoy E, Kirankaya S, Kokkola T, Emecen G et al. Natural thermal adaptation increases heat shock protein levels and decreases oxidative stress. Redox Biol 2014; 3: 25-28.

41 Kondrikov D, Fulton D, Dong Z, Su Y. Heat shock protein 70 prevents hyperoxia-induced disruption of lung endothelial barrier via caspasedependent and AIF-dependent pathways. PLOS ONE 2015; 10: e0129343.

42 Yurinskaya MM, Mitkevich VA, Kozin SA, Evgen'ev MB, Makarov AA, Vinokurov MG. HSP70 protects human neuroblastoma cells from apoptosis and oxidative stress induced by amyloid peptide isoAsp7-Abeta(1-42). Cell Death Dis 2015; 6: e1977.
43 Davies KJ. Protein damage and degradation by oxygen radicals. I. general aspects. J Biol Chem 1987; 262: 9895-9901.

44 Grune T, Reinheckel T, Davies KJ. Degradation of oxidized proteins in mammalian cells. FASEB J 1997; 11: 526-534.

45 Sisoula C, Gonos ES. CHIP E3 ligase regulates mammalian senescence by modulating the levels of oxidized proteins. Mech Ageing Dev 2011; 132: 269-272.

46 Lee JS, Seo TW, Yi JH, Shin KS, Yoo SJ. CHIP has a protective role against oxidative stress-induced cell death through specific regulation of endonuclease G. Cell Death Dis 2013; 4: e666.

47 Du ZX, Zhang HY, Meng X, Gao YY, Zou RL, Liu BQ et al. Proteasome inhibitor MG132 induces BAG3 expression through activation of heat shock factor 1. J Cell Physiol 2009; 218: 631-637.

48 Chen Y, Yang LN, Cheng L, Tu S, Guo SJ, Le HY et al. Bcl2-associated athanogene 3 interactome analysis reveals a new role in modulating proteasome activity. Mol Cell Proteomics 2013; 12: 2804-2819.

49 Jin YH, Ahn SG, Kim SA. BAG3 affects the nucleocytoplasmic shuttling of HSF1 upon heat stress. Biochem Biophys Res Commun 2015; 464: 561-567.

50 Bruce JL, Price BD, Coleman CN, Calderwood SK. Oxidative injury rapidly activates the heat shock transcription factor but fails to increase levels of heat shock proteins. Cancer Res 1993; 53: 12-15.

51 Sandoval-Montiel AA, Zentella-de-Pina M, Ventura-Gallegos JL, FriasGonzalez S, Lopez-Macay A, Zentella-Dehesa A. HSP-72 accelerated expression in mononuclear cells induced in vivo by acetyl salicylic acid can be reproduced in vitro when combined with H2O2. PLOS ONE 2013; 8: e65449.

52 Adachi M, Liu Y, Fujii K, Calderwood SK, Nakai A, Imai K et al. Oxidative stress impairs the heat stress response and delays unfolded protein recovery. PLOS ONE 2009; 4: e7719.

53 Jacquier-Sarlin MR, Polla BS. Dual regulation of heat-shock transcription factor (HSF) activation and DNA-binding activity by $\mathrm{H} 2 \mathrm{O} 2$ : role of thioredoxin. Biochem J 1996; 318 (Pt 1): 187-193.

$54 \mathrm{Li}$ Y, Roth S, Laser M, Ma JX, Crosson CE. Retinal preconditioning and the induction of heat-shock protein 27. Invest Ophthalmol Vis Sci 2003; 44: 1299-1304.

55 Awasthi N, Wagner BJ. Upregulation of heat shock protein expression by proteasome inhibition: an antiapoptotic mechanism in the lens. Invest Ophthalmol Vis Sci 2005; 46: 2082-2091.

(1) () $\odot$ This work is licensed under a Creative Commons Attribution-NonCommercial-NoDerivs 4.0 International License. The images or other third party material in this article are included in the article's Creative Commons license, unless indicated otherwise in the credit line; if the material is not included under the Creative Commons license, users will need to obtain permission from the license holder to reproduce the material. To view a copy of this license, visit http://creativecommons.org/licenses/by-nc-nd/4.0/ 